\title{
Effects of general anesthesia with or without epidural block on tumor metastasis and mechanisms
}

\author{
BIN YANG ${ }^{1}$, FENG QIAN $^{2}$, WENJIA LI $^{1}$, YANG LI $^{1}$ and YANGDONG HAN ${ }^{2}$ \\ Departments of ${ }^{1}$ Breast Surgery and ${ }^{2}$ Anesthesiology, China-Japan Union Hospital of Jilin University, \\ Changchun, Jilin 130033, P.R. China
}

Received May 24, 2016; Accepted November 10, 2017

DOI: $10.3892 / \mathrm{ol} .2018 .7870$

\begin{abstract}
The present study aimed to assess whether different anesthesia methods (general anesthesia and general anesthesia combined with epidural block) were associated with tumor metastasis during the perioperative period and the possible molecular mechanisms of tumor metastasis. A rat hepatoma tumor xenograft model was constructed via the subcutaneous injection of Morris hepatoma 3924A cells into the upper axillary fossa. General anesthesia and general anesthesia combined with epidural block prior to hepatectomy were conducted on tumor-bearing rats. The average numbers of metastatic nodules on the lung surface were calculated in the different groups and the presence of abdominal lymph node metastases, rate of malignant ascites and abdominal wall-implanted nodules were recorded. Blood samples were collected from the orbits of rats immediately prior to surgery and at 2, 7 and 30 days following surgery. Plasma levels of interferon- $\gamma$, transforming growth factor- $\alpha$ and vascular endothelial growth factor (VEGF) were measured. Finally, the expression of phosphorylated signal transducer and activator of transcription-3 and phosphorylated VEGF were measured by western blot analysis. The results of this analysis demonstrated that tumor metastasis was greatly suppressed when the rats underwent general anesthesia combined with epidural block prior to hepatectomy, compared with general anesthesia alone. The results of cytokine quantification and western blot analysis revealed that the anti-metastatic effect of general anesthesia combined with epidural block may have been mediated by inhibition of STAT3 and the relevant cytokines.
\end{abstract}

Correspondence to: Dr Yangdong Han, Department of Anesthesiology, China-Japan Union Hospital of Jilin University, 126 Sendai Street, Changchun, Jilin 130033, P.R. China

E-mail: hydsubmission@163.com

Key words: general anesthesia, general anesthesia combined with epidural block, signal transducer and activator of transcription 3, tumor metastasis, antitumor mechanism

\section{Introduction}

Primary liver cancer has the fifth-highest incidence of malignant tumors and is the third-leading cause of cancer-associated mortality, $90 \%$ of cases are hepatocellular carcinoma (HCC) (1). In certain areas of Asia and the Middle East, HCC ranks as the leading cause of cancer-associated mortality (2). Surgical resection, which is the first-choice treatment modality for HCC, can significantly improve the prognosis and prolong the survival time of patients. However, surgery inevitably induces neuroendocrine, metabolic and inflammatory responses $(3,4)$, directly affecting post-operative recovery and the survival time of patients $(5,6)$. Consequently, the induction of this immune response can be injurious to long-term prognosis during the perioperative period. Therefore, the perioperative period is a critical period for long-term prognosis. The primary method of improving the long-term prognosis of tumor patients is to understand the mechanisms of tumor metastasis and corresponding immune responses. Recently, substantial attention has been paid to the association between methods of anesthesia and long-term prognosis (7). As an important role in the whole perioperative period, the responsibility of the anesthetists to improve the long-term prognosis of cancer patients has been increasingly appreciated in recent years (8). Metastasis is one of the most important characteristics of malignant tumors, serving an important role in treatment efficacy and quality of life of patients (9). The metastasis of tumors comprises of a complex series of events and can be divided into a number of sequential steps: i) Release from the primary tumor and invasion into the surrounding tissues; ii) intravasation; iii) transition in the blood circulation; iv) arrest in the capillary bed; v) extravasation; and vi) growth at preferred sites (10). In this cascade, angiogenesis, the formation of a new blood supply from pre-existing vasculature, is a critical step of tumor metastasis (11). Angiogenesis is a complex multistage process that is regulated by the balance between angiogenic and angiostatic factors (12-14). Among these associated factors, vascular endothelial growth factor (VEGF) has been demonstrated to be one of the most important angiogenic mediators (15). VEGF is the most commonly studied angiogenic mediator and has been well established as a molecular target in clinical studies $(16,17)$ In addition to its role in stimulating angiogenesis, VEGF induces vascular permeability to circulating macromolecules (16). Previous studies $(18,19)$ have shown that signal transducer and 
activator of transcription 3 (STAT3) regulates angiogenesis primarily by modulating VEGF expression, although several other candidates affected by STAT3 have been reported to show distinct effects on angiogenesis.

General anesthesia (GA) and GA combined with epidural block (GEA) are the most commonly anesthetic methods in hepatectomy. GEA can prevent or attenuate the surgical stress response by blocking afferent neural transmission, which prevents harmful afferent input from reaching the central nervous system $(20)$. Previous studies $(21,22)$ have shown that the choice of anesthesia methods was only associated with perioperative stress and immune function for a short time. However, animal experiments and clinical studies $(23,24)$ in recent years have reported that different anesthetic methods serve important roles in cancer recurrence or metastasis. Compared with GA, GEA significantly reduces the dependency on opioids (25). Opioids, including morphine, one of the most commonly used, can inhibit cellular and humoral immune function (26,27). An animal study (28) strongly indicated that opioids, including morphine and fentanyl, can promote tumor metastasis and recurrence. Clinical trials $(29,30)$ have demonstrated that morphine can accelerate the growth of breast tumors. Consequently, paravertebral anesthesia and analgesia combined with GA led to a lower incidence of cancer recurrence or metastasis. Recent research indicates that the association of opioids with tumor behavior is complex and remains unclear (31).

The present study compared the anti-metastatic effect of GA and GEA on tumor-bearing rats with hepatectomy. The results revealed that the anti-metastatic effect of GEA is significant superior to GA. Furthermore, the mechanism of the two anesthesia methods on tumor metastasis and angiogenesis was investigated. As the results of the present study demonstrate, one possible mechanism by which GEA suppresses tumor metastasis and angiogenesis is the improvement of the expression of interferon- $\gamma($ IFN- $\gamma)$ and the inhibition of transforming growth factor- $\alpha$ (TGF- $\alpha$ ), VEGF and p-STAT3.

\section{Materials and methods}

Materials. The rat hepatic cancer cell line Morris hepatoma 3924A was purchased from American Type Culture Collection (Manassas, VA, USA) Morphine, bupivacaine and fentanyl were purchased from Shanghai Sangon Biotechnology Co., Ltd. (Shanghai, China). The cell line was cultured at $37^{\circ} \mathrm{C}$ in a humidified atmosphere containing $5 \% \mathrm{CO}_{2}$ in Dulbecco's modified Eagle's medium with $10 \%$ fetal bovine serum (FBS), $100 \mathrm{U} \mathrm{ml}^{-1}$ penicillin and $100 \mathrm{mg} \mathrm{ml}^{-1}$ streptomycin (Gibco; Thermo Fisher Scientific, Inc., Waltham, MA, USA), 30 male American Certification Institute (ACI) rats (age, 12-18 weeks; weight, 200-250 g) were purchased from the Experimental Animal Center of Changchun Biological Institute (Changchun, China), and they were housed at a temperature of $20-22^{\circ} \mathrm{C}$, relative humidity of $50-60 \%$ and $12 / 12 \mathrm{~h}$ light/dark cycles. They were also provided with free access to food and water. The 7-0 injury-free operative sutures were purchased from Shanghai Surgical Suture Company. ELISA kit and antibodies used in the present study were purchased from Invitrogen (Thermo Fisher Scientific, Inc.). Details were as follows: IFN- $\gamma$ ELISA kit (cat no. BMS621); TGF- $\alpha$ ELISA kit (cat no. EHTGFA);
VEGF ELISA kit (cat no. ERVEGFACL); phospho-STAT3 (Tyr705) polyclonal antibody (cat no. 44-380G; dilution, 1:1,000); and phospho-EGFR (Tyr1086) polyclonal antibody (cat no. 36-9700; dilution, 1:500). The anti-rabbit IgG secondary antibody, horseradish peroxidase (cat no. P7899; dilution, 1:100,000) was provided by Sigma-Aldrich (Merck KGaA; Darmstadt, Germany).

Animals and the tumor xenograft model. All animal experiments were performed in compliance with the Animal Management Rules of the Ministry of Health of the People's Republic of China (http://www.medste. gd.cn/Html/sciedu/sysgl/Class3141/24961720080910094400. html) and approved by the Animal Care and Use Committee of Jilin University (Changchun, China). All animals were pathogen-free and allowed ad libitum access to food and water. To produce the tumor xenograft model, MH3924A cells in the logarithmic phase were injected subcutaneously into the upper axillary fossa of the male ACI rats (12-18 weeks, $n=10$ per group). After 14 days, subcutaneous tumors were surgically removed. Fresh tumor tissues were chosen and divided into $1-\mathrm{mm}^{3}$ tumor pieces. The male rats were fixed on a frame prior to anesthesia, then the abdominal body hair was removed and the animals were disinfected with iodine. A 5-ml syringe was placed at the back of the fixed rats to raise the abdomen of the rats for surgical convenience. Next, when the size of incision in upper abdomen reached $\sim 0.5 \mathrm{~cm}$, the skin, subcutaneous tissue and peritoneal tissue was consecutively cut and then the rat liver was exposed. The left lobe was cleaned with wet cotton and the liver capsule was punctured with ophthalmic scissors, making a further long cut under the capsule. Next, the as-prepared tumor tissue was inserted into the long cut, which was closed with 7-0 microscopic sutures. Prior to abdominal closure, it should be confirmed that there was no blister tissue out and no bleeding.

GEA. When the tumor volume reached $\sim 300 \mathrm{~mm}^{3}$, these tumor-bearing rats were randomly divided into three treatment groups: One group was treated with hepatectomy and general anesthesia combined with epidural block (group $\mathrm{G}+\mathrm{E}$ ), one group was treated with hepatectomy and general anesthesia (group G) and one group, the control group, did not undergo any treatment (group C). There were 10 rats included in each group.

$G A$. A simple tumor resection was performed under general anesthesia. Specifically, sevoflurane together with oxygen was injected into a self-made anesthesia box. Next, the retraction response of rat toes to stimulus was continuously assessed to determine the degree of anesthesia. When the retraction response of rat toes to stimulus disappeared, tracheal incubation was conducted for the rat by transmission light intubation. Specifically, the 50-W illuminant was placed $5 \mathrm{~cm}$ away from the neck of the rat. In this way, the light could pass through the neck skin and trachea wall in sequence. A mini sized spatula with a $145^{\circ}$ angle were used to push away the tongue for clear observation of the epiglottis and vocal cord movement under the transmitted light, thus an $18 \mathrm{G}$ cannula was inserted under a bright view. The regular movement of the rat thorax was observed following connection with the ventilator with 
mechanical ventilation. The parameters of the ventilator were set as follows: Breathing rate, 55/min; tidal volume, $3 \mathrm{ml} / 100 \mathrm{~g}$; inspiration rate: expiration rate, 1.5:1; sevoflurane concentration, $2-3 \%(\mathrm{v} / \mathrm{v})$. To maintain the anesthesia effect, morphine $(0.2 \mathrm{ml} / 100 \mathrm{~g}, 10 \%$ solution) was injected intraperitoneally. When the rats woke following surgery, the endotracheal tube was removed.

Epidural anesthesia. Perioperative epidural analgesia consisted of a bolus of $6-9 \mathrm{ml}$ of $0.25 \%$ bupivacaine followed by a postoperative infusion of bupivacaine (0.1-0.2\%) with or without $2 \mu \mathrm{g} / \mathrm{ml}$ of fentanyl at a rate of $6-9 \mathrm{ml} / \mathrm{h}$. Specifically, the limbs and head of the rat were fixed following the success of tracheal incubation under general anesthesia. A self-made sterile PVC epidural catheter with diameter of $0.3 \mathrm{~mm}$ was inserted via removing the eighth or ninth thoracic spinous process using a vertical needling and was advanced $1 \mathrm{~cm}$ cephalad into the epidural space. Subsequently, $0.25 \%$ of bupivacaine was micro-injected via the epidural catheter.

Hepatectomy. According to observations, the tumor size was suitable for hepatectomy and no distant metastasis was observed at day 14 following inoculation with tumor cells. Hepatectomy was conducted following successful anesthesia with the assistance of undergraduate students majoring in liver surgery (Departments of General Surgery, China-Japan Union Hospital Jilin University, Changchun, China). Specifically, the skin, subcutaneous tissue and peritoneal tissue was consecutively removed from the original upper abdomen incision. Next, the left lobe of the liver was exposed and the megascopic in situ tumor tissue was removed, as was $5 \mathrm{~mm}$ normal liver tissue around the edge of tumor. The 7-0 microscopic suture was used to close the abdomen following the confirmation of no bleeding.

Blood sample collection and ELISA assay. Venous blood samples were collected from orbits of rats immediately prior to surgery and at 2, 7 and 30 days following surgery. The blood samples were left to clot at room temperature and then stored overnight in a refrigerator to contract the clot. The clot was removed and the remaining material was centrifuged at $4,000 \mathrm{x}$ g for $5 \mathrm{~min}$ and the resulting serum was stored at $-80^{\circ} \mathrm{C}$ until analysis. Plasma levels of IFN- $\gamma$, TGF- $\alpha$ and VEGF were measured by an ELISA. Plasma levels of each cytokine were measured in duplicate from one aliquot of each sample and the mean value from these two measurements was used as the final concentration. Quantification was achieved using an automated microplate reader. Concentrations of all cytokines were reported in $\mathrm{pg} / \mathrm{ml}$. The rats were sacrificed 30 days following surgery. The lungs were removed and collected for the following experiments. The metastatic nodes in the lungs of mice were visualized by fixing them in Bouin's solution (saturated picric acid: Formalin: Acetic acid, 15:5:1) at room temperature for $24 \mathrm{~h}$ and photographed using a high-definition digital camera (IXUS 110, Canon Inc., Tokyo, Japan) to evaluate the anti-metastatic effects of general anesthetic and general anesthetic with epidural block.

Western blot analysis. For each group, $0.1 \mathrm{~g}$ of the lung tissue was collected for protein extraction and lysed using a Dounce
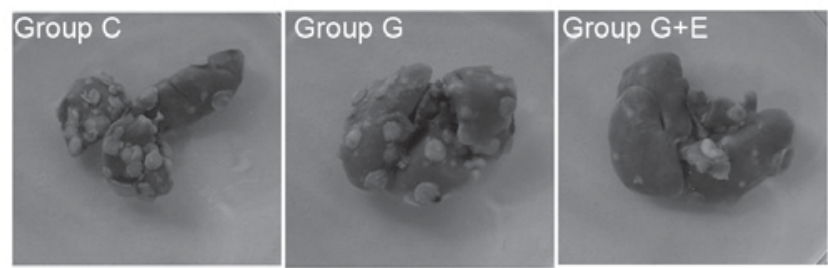

Figure 1. The numbers of the lung metastasis nodes were observed and imaged using a camera after fixing with Bouin's solution.

homogenizer (20 strokes) in $400 \mu \mathrm{l}$ of buffer containing $50 \mathrm{mM}$ tris (hydroxymethyl) aminomethane hydrochloride (Tris- $\mathrm{HCl}$ ), $\mathrm{pH} 7.6,42 \mathrm{mM} \mathrm{KCl,} 5 \mathrm{mM} \mathrm{MgCl} \mathrm{m}_{2}, 1 \mathrm{mM}$ dithiothreitol (DTT), 0.5\% 3-[(3-cholamidopropyl) dimethyl ammonio]-1-propanesulfonate hydrate, $1 \mathrm{mM}$ phenylmethylsulfonyl-fluoride and $1 \mu \mathrm{g} / \mathrm{ml}$ leupeptin (Sigma-Aldrich; Merck $\mathrm{KGaA}$ ), and then centrifuged at $15,000 \mathrm{x} \mathrm{g}$ for $20 \mathrm{~min}$ at $4^{\circ} \mathrm{C}$. The protein concentrations of the lysates were determined by BCA protein assay. Equal amounts $(50 \mu \mathrm{g})$ of protein were separated on a $10 \%$ SDS-PAGE and transferred onto polyvinylidene difluoride membranes. The membranes were blocked with $5 \%$ non-fat milk in Tris-buffered saline/ $0.1 \%$ Tween-20 for $2 \mathrm{~h}$, subsequently blotted with respective primary antibodies overnight at $4^{\circ} \mathrm{C}$ as described previously in the materials section, and then blotted with horseradish peroxidase-conjugated secondary antibody at $37^{\circ} \mathrm{C}$ for $1 \mathrm{~h}$. The protein bands were visualized using an enhanced chemiluminescent agent (Fuzhou Maixin Biotech Co., Ltd., Fuzhou, China). Protein levels were quantified by density analysis using ImageJ software version 1.62 (National Institutes of Health, Bethesda, MD, USA), and expressed as the interest protein/internal control.

Statistical analysis. Data from $\geq 3$ groups were compared using one-way analysis of variance followed by Dunnett's post-hoc test using the SPSS software package (version 13.0; SPSS Inc., Chicago, IL, USA). The experiments were performed in triplicate and the data are presented as the mean \pm standard deviation. $\mathrm{P}<0.05$ was considered to indicate a statistically significant difference.

\section{Results}

The anti-metastatic effects of GA and GEA. The evaluation on the in vivo anti-metastatic activity of general anesthesia and epidural anesthesia was performed. In the in vivo experiment, the rats were sacrificed 30 days after surgery and the lungs were dissected. The average numbers of metastatic nodules on the lung surface in different groups were counted. Representative photos of the lungs with the metastatic nudes are presented in Fig. 1. As depicted in Table I, the number of metastasis nodules in the $\mathrm{G}+\mathrm{E}$ group was $18 \pm 6$, which was significantly $(\mathrm{P}<0.05)$ less than that in group $\mathrm{C}(40 \pm 6)$ or group $\mathrm{G}(38 \pm 5)$. This result indicated that GEA could effectively inhibit lung metastasis compared with GA following hepatectomy. The conditions of abdominal lymph node metastasis, the rate of malignant ascites and number of abdominal wall planting nodules also validated this conclusion. As presented in Table I, the number of animals for which there was a presence of abdominal lymph node 
Table I. Quantified data of metastases analysis $(\mathrm{n}=10)$.

\begin{tabular}{|c|c|c|c|c|c|}
\hline Groups & $\begin{array}{l}\text { Lung } \\
\text { metastases }^{\mathrm{a}}, \mathrm{n}\end{array}$ & $\begin{array}{l}\text { Abdominal lymph } \\
\text { node metastasis, } \mathrm{n}\end{array}$ & $\begin{array}{l}\text { Rate of } \\
\text { malignant ascites, } \mathrm{n}\end{array}$ & $\begin{array}{c}\text { Abdominal wall-implanted } \\
\text { nodules, } \mathrm{n}\end{array}$ & $\begin{array}{l}\text { Volumes of lung } \\
\text { with all metastases }{ }^{\mathrm{a}}, \mathrm{cm}^{3}\end{array}$ \\
\hline Group C & $40 \pm 6$ & $7 / 10$ & $8 / 10$ & $8 / 10$ & $14.85 \pm 1.66$ \\
\hline Group $\mathrm{G}+\mathrm{E}$ & $18 \pm 6^{\mathrm{b}, \mathrm{c}}$ & $1 / 10^{\mathrm{b}, \mathrm{c}}$ & $2 / 10^{\mathrm{b}, \mathrm{c}}$ & $2 / 10^{\mathrm{b}, \mathrm{c}}$ & $12.93 \pm 1.52$ \\
\hline Group G & $38 \pm 5$ & $6 / 10$ & $7 / 10$ & $5 / 10$ & $13.06 \pm 2.08$ \\
\hline
\end{tabular}

${ }^{\mathrm{a}}$ Mean \pm standard deviation. ${ }^{\mathrm{b}} \mathrm{P}<0.05$ vs. group $\mathrm{G}$; ${ }^{\mathrm{c}} \mathrm{P}<0.05$ vs. group $\mathrm{C}$. Group $\mathrm{C}$, rats that did not undergo hepatectomy; group $\mathrm{G}+\mathrm{E}$, rats that underwent hepatectomy under general anesthetic with epidural block; group $\mathrm{G}$, rats that underwent hepatectomy under general anesthetic.
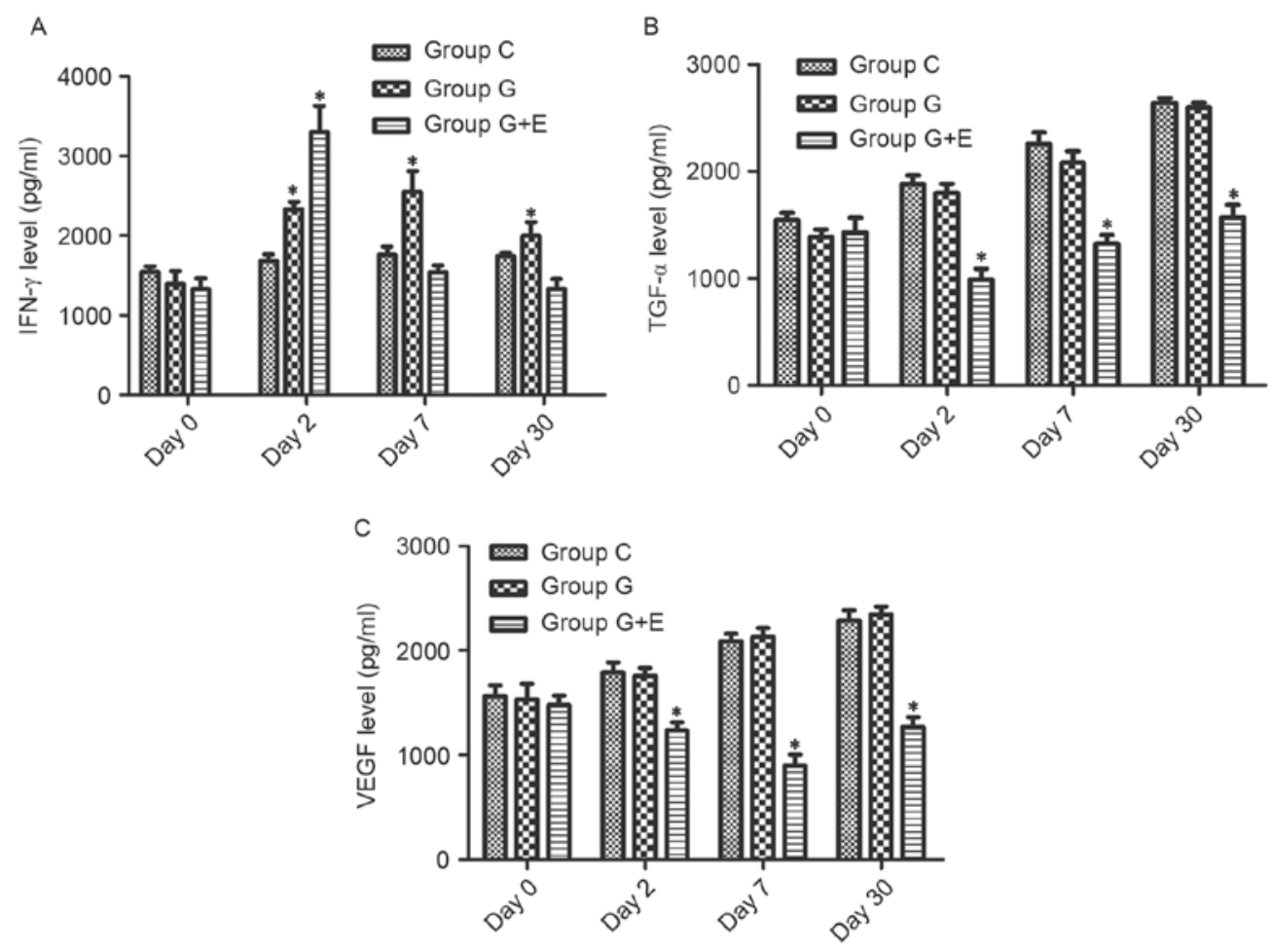

Figure 2. Changes in cytokine concentration in serum of rats that underwent different treatments. The changes in (A) IFN- $\gamma$, (B) TGF- $\alpha$ and (C) VEGF concentration in tumor-bearing rats in groups $\mathrm{C}, \mathrm{G}$ and $\mathrm{G}+\mathrm{E}$. $\mathrm{P}<0.05$. IFN- $\gamma$, interferon- $\gamma$; TGF- $\alpha$, transforming growth factor- $\alpha$; VEGF, vascular endothelial growth factor; group C, rats that did not undergo hepatectomy; group $\mathrm{G}+\mathrm{E}$, rats that underwent hepatectomy under general anesthetic with epidural block; group $\mathrm{G}$, rats that underwent hepatectomy under general anesthetic.

metastasis was significantly lower for group $G+E(1 / 10)$ than for group C (7/10) or group $\mathrm{G}(6 / 10)$. For group $C$ and group $\mathrm{G}$, the rates of malignant ascites were higher than that of group $\mathrm{G}+\mathrm{E}$, which demonstrated the low metastatic rate following surgery with epidural anesthesia. Abdominal wall-implanted nodules represented another important evaluation index for metastatic condition. According to Table I, the number of rats with abdominal wall-implanted nodules in group $\mathrm{G}+\mathrm{E}$ was $2 / 10$, which was significantly lower than that for group $C(8 / 10)$ or group $\mathrm{G}(5 / 10)$. Hepatectomy with different anesthetic techniques revealed different rates of tumor metastasis. Notably, GEA could effectively inhibit tumor metastasis compared to GA following hepatectomy.

Changes in cytokine concentration in the serum of rats that underwent different treatments determined by ELISA. As shown in Fig. 2A, there was no significant difference in IFN- $\gamma$ levels between groups $\mathrm{C}, \mathrm{G}$ and $\mathrm{G}+\mathrm{E}$ on day 0 . On day 2 , the concentration of IFN- $\gamma$ in group $\mathrm{G}+\mathrm{E}(3,411 \pm 232 \mathrm{pg} / \mathrm{ml})$ was significantly higher than that in group C $(1,497 \pm 146 \mathrm{pg} / \mathrm{ml})$ and $\mathrm{G}(2,578 \pm 165 \mathrm{pg} / \mathrm{ml})$. On day 7 and day 30 , there was no significant difference between group $\mathrm{C}$ and $\mathrm{G}$, but these concentrations were significantly higher than those in group $\mathrm{G}+\mathrm{E}$. For group $\mathrm{G}+\mathrm{E}$, the concentration of IFN- $\gamma$ at day 7 and day 30 was slightly lower than that on day 2. Similarly, there was no significant difference in regard to concentrations of TGF- $\alpha$ and VEGF between group $\mathrm{C}, \mathrm{G}$ and $\mathrm{G}+\mathrm{E}$ on day 0 (Fig. 2B and $\mathrm{C}$ ). On the following days, concentrations of TGF- $\alpha$ and VEGF were significantly lower in group $\mathrm{G}+\mathrm{E}$ than in groups $\mathrm{C}$ and $\mathrm{G}(\mathrm{P}<0.05)$. Notably, the concentration of TGF- $\alpha$ increased slowly over time following surgery. However, the concentration of VEGF was at its minimum on day 7. Groups $\mathrm{C}$ and $\mathrm{G}$ exhibited increases in the concentration of TGF- $\alpha$ and VEGF, whereas the concentration 


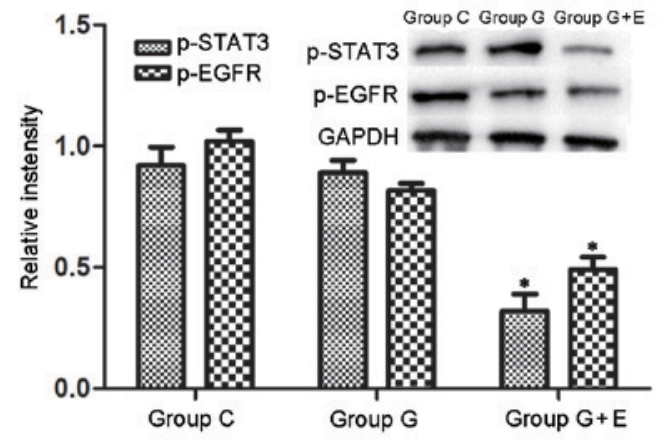

Figure 3. Western blot analysis. Levels of p-STAT3 and p-EGFR in tumor-bearing rats treated with and without GA and GEA. " $\mathrm{P}<0.05$. p-STAT3, phosphorylated signal transducer and activator of transcription 3; EGFR, epidermal growth factor receptor; group C, rats that did not undergo hepatectomy; group $\mathrm{G}+\mathrm{E}$, rats that underwent hepatectomy under genera anesthetic with epidural block; group $\mathrm{G}$, rats that underwent hepatectomy under general anesthetic.

in group $\mathrm{G}+\mathrm{E}$ rats remained lower than those in groups $\mathrm{C}$ and $\mathrm{G}$.

Levels of phosphorylated STAT3 (p-STAT3) and p-VEGF in lung metastasis tissues determined by western blot analysis. To investigate the mechanism of the anesthesia-induced anti-metastatic effect further, levels of p-STAT3 and p-EGFR lung metastatic tissues were determined by western blot analysis (Fig. 3). The levels of p-STAT3 and p-EGFR in group $\mathrm{G}$ were slightly lower than those in group $\mathrm{C}$. It was shown that there were significantly $(\mathrm{P}<0.05)$ lower levels of $\mathrm{p}$-STAT3 and p-EGFR in group $\mathrm{G}+\mathrm{E}$ than in groups $\mathrm{C}$ and $\mathrm{G}$. Evidence indicates that aberrant STAT3 signaling promotes the initiation and progression of human cancer by either inhibiting apoptosis or inducing cell proliferation, angiogenesis, invasion and metastasis (32-34). Additionally, expression of EGFR is altered in a variety of human cancer types, including carcinoma of the lung, breast, head and neck, ovary and bladder, as well as in glioma (35-37). STAT3 and EGFR serve notable roles in tumor development and metastasis $(34,38)$. The results of the present study indicated that GEA significantly inhibited tumor metastasis by reducing levels of p-STAT3 and p-EGFR.

\section{Discussion}

The perioperative period is a critical period of damage to the body's defense mechanism and has a substantial influence on the long-term prognosis of tumor patients. The role of anesthesia in improving the long-term prognosis of patients following surgery has been known and taken seriously in recent years.

It has been reported that there are four major mechanisms that surgery could contribute to an increase in tumor metastasis: i) The operation and touch of the tumor during surgery increased the chance of tumor cells releasing into the bloodstream (39); ii) Tumors in situ (TIS) serve a role in inhibiting angiogenesis: In surgery, the resection of TIS disrupts this line of defense, with the residual lesions promoting diseases and inducing the growth of blood vessels to increase the risk of tumor metastasis (40); iii) Perioperative immune suppression: Levels of epinephrine and norepinephrine during the perioperative period are substantially increased, which is considered to be the key to the connection between stress response and cancer progression (41); iv) The increase in local and systemic growth factor (EGF and VEGF) release in surgery promotes the recurrence of local and distant tumors (42). Furthermore, anti-angiogenic factors, including angiostatin and endostatin, decrease during surgery (43). Catecholamine promotes growth in a variety of tumor types by activating the STAT3 signaling pathway to increase the level of VEGF and inhibit the cellular immune response (5).

In the present study, the levels of IFN- $\gamma$ in the plasma of rats in group $\mathrm{G}+\mathrm{E}$ were higher than those in the two other groups, whereas the levels of VEGF and TGF- $\alpha$ in group $\mathrm{G}+\mathrm{E}$ were lower than those in other two groups, as was the degree of STAT3 activation. The present study indicates that compared with GA, GEA can reduce the incidence of liver cancer metastasis following surgery. A possible mechanism may include the inhibition of STAT3 and relevant cytokines, including IFN- $\gamma$ and TGF- $\alpha$.

IFN- $\gamma$, which is secreted by $\mathrm{T}$ cells, can suppress tumor cell proliferation, upregulate the expression of surface major histocompatibility complex antigens and tumor necrosis factor and prevent tumor growth via inhibition of tumor angiogenesis and other mechanisms (44). A previous study demonstrated that IFN- $\gamma$ can decrease the defense of tumors cells escaping immune system by regulating expression of the Fas cell surface death receptor/Fas ligand and enhancing sensitivity to Fas-mediated apoptosis, thus inhibiting the malignant proliferation of tumor cells (45).

EGFR is a membrane-bound receptor tyrosine kinase that belongs to the ErbB subfamily (46). On ligand binding, EGFR initiates the activation of a series of cellular signal transduction pathways that regulate cell proliferation and survival (47). The primary ligands for EGFR include EGF and TGF- $\alpha$ in liver cells (48). TGF- $\alpha$ produced by liver cells can bind with EGFR to promote the proliferation of liver cells by autocrine, or increase the proliferation of the vascular endothelium by paracrine (6). EGFR is activated by ligand binding, which causes it to homodimerize, activating downstream pathways, including the RAS proto-oncogene, GTPase/Raf proto-oncogene, serine/threonine kinase mitogen-activated protein kinase pathway, the Janus kinase (JAK)/STAT pathway and the phosphoinositide 3-kinase/RAC serine/threonine-protein kinase pathway (49). Two possible pathways for STAT3 activation exist, a JAK-dependent mechanism and a JAK-independent one, which initiates dimer formation of STAT3 in the cytoplasm. Thereafter, activated STAT3 transfers into the nucleus, binds to specific DNA sequences and induces transcription of target genes $(47,50)$. This sequential process promotes tumor cell proliferation and inhibits apoptosis by regulating expression of the apoptosis suppressor genes, such as MCL1, BCL2 family apoptosis regulator and BCL2-like 1, and cell cycle regulatory factors, such as cyclin D1/D2 and MYC proto-oncogene, BHLH transcription factor (3).

In the present study, the expression levels of VEGF and TGF- $\alpha$ in group $C$ were significantly higher than those in group $\mathrm{G}$; however, those in group $\mathrm{G}$ were higher than those in group $\mathrm{G}+\mathrm{E}$. Overexpression of EGFR and its relevant ligands or the sequential activation of downstream signal pathways is observed in numerous tumor types $(37,38)$. The formation of tumors is promoted by the following methods: Overexpression 
of EGFR triggers the enhancement of downstream signal transduction (51); the mutation of EGFR or overexpression of its ligands results in continuous EGFR activation (52); the function of autocrine loop is enhanced (53), mechanisms of downregulation of oncogenic receptors are lost (54); and abnormal signal transduction pathways are activated (55). In the present study, the increase in the expression of EGFR and its ligand demonstrated that the EGFR signal transduction pathway alters the formation of liver cancer metastasis via at least two mechanisms: The overexpression of TGF- $\alpha$ and EGFR, leading to the formation of an autocrine loop and increased downstream signal transduction, respectively. STAT3 is an oncogene that is closely associated with tumor development, evolvement, differentiation and immunity $(18,19)$. The sustained activation or overexpression of STAT3 is frequently observed in skin, lung and breast cancer (56). To the best of our knowledge, mutations to STAT3 have not yet been observed, so we hypothesize that the sustained activation of STAT3 is triggered by enhancement of the intensity of upstream signal transduction pathways.

Song and Grandis (57) demonstrated that cell lines overexpressing TGF- $\alpha$ exhibited sustained activation of STAT3, and the addition of exogenous TGF- $\alpha$ could enhance the activation of squamous cell carcinoma of the head and neck. For certain tumors, the sustained activation of STAT3 resulted in the enhancement of activation of EGFR signal transduction pathways (57). STAT3 binds to activated EGFR via SH2 domains; stimulation of EGFR induces Tyr705 phosphorylation of STAT3, which is a prerequisite for dimerization of STATs, which again occurs via the SH2 domains (58). The dimerization of tyrosine-phosphorylated STATs leads to their nuclear accumulation, DNA binding at specific sites and the transcriptional activation of target genes (57). Research on breast cancer, squamous cell carcinoma of the head and neck and epidermoid cancer has revealed that sustained activation of STAT3 is relevant to the formation of the EGFR/TGF- $\alpha$ autocrine loop (59-61).

The present study revealed that the metastasis of liver cancer was decreased in rats that underwent surgery with GEA compared with those that underwent GA. The results demonstrated that the mechanism by which this occurred may be associated with the inhibition of STAT3 and certain relevant cytokines. However, these results were obtained from animal experiments, which require careful consideration and further confirmation in clinical trials.

\section{References}

1. Zhu RX, Seto WK, Lai CL and Yuen MF: Epidemiology of hepatocellular carcinoma in the Asia-pacific region. Gut Liver 10 332-339, 2016

2. Llovet JM: Updated treatment approach to hepatocellular carcinoma. J Gastroenterol 40: 225-235, 2005.

3. Buggy DJ and Smith G: Epidural anesthesia and analgesia: Better outcome after major surgery? Growing evidence suggests so. BMJ 319: 530-531, 1999.

4. Ogawa K, Hirai M, Katsube T, Murayama M, Hamaguchi K, Shimakawa T, Naritake Y, Hosokawa T and Kajiwara T: Suppression of cellular immunity by surgical stress. Surgery 127 : 329-336, 2000

5. Ben-Eliyahu S: The price of anticancer intervention. Does surgery promote metastasis? Lancet Oncol 3: 578-579, 2002.

6. Ben-Eliyahu S, Page GG, Yirmiya R and Shakhar G: Evidence that stress and surgical interventions promote tumor development by suppressing natural killer cell activity. Int J Cancer 80 : 880-888, 1999 .
7. Deiner S and Silverstein JH: Long-term outcomes in elderly surgical patients. Mt Sinai J Med 79: 95-106, 2012.

8. Deflandre E and Lacroix S: It is time for anesthetists to act as perioperative physicians. Minerva Anestesiol 82: 257-258, 2016.

9. Martin TA, Ye L, Sanders AJ, Lane J and Jiang WG: Cancer invasion and metastasis: Molecular and cellular perspective. In: Metastatic Cancer Clinical Biological Perspectives 2013. Jandial R (ed). Landes Bioscience, Austin, TX, pp. 135-168, 2013.

10. Tsuchiya Y, Sawada S, Yoshioka I, Ohashi Y, Matsuo M, Harimaya Y, Tsukada K and Saiki I: Increased surgical stress promotes tumor metastasis. Surgery 133: 547-555, 2003.

11. Ucuzian AA, Gassman AA, East AT and Greisler HP Molecular mediators of angiogenesis. J Burn Care Res 31: 158-175, 2010.

12. Distler JH, Hirth A, Kurowska-Stolarska M, Gay RE, Gay S and Distler O: Angiogenic and angiostatic factors in the molecular control of angiogenesis. Q J Nucl Med 47: 149-161, 2003.

13. Simons M: Integrative signaling in angiogenesis. Mol Cell Biochem 264: 99-102, 2004.

14. Chen Z and Han ZC: STAT3: A critical transcription activator in angiogenesis. Med Res Rev 28: 185-200, 2008.

15. Hoeben A, Landuyt B, Highley MS, Wildiers H, Van Oosterom AT and De Bruijn EA: Vascular endothelial growth factor and angiogenesis. Pharmacol Rev 56: 549-580, 2004.

16. Senger DR, Galli SJ, Dvorak AM, Perruzzi CA, Harvey VS and Dvorak HF: Tumor cells secrete a vascular permeability factor that promotes accumulation of ascites fluid. Science 219: 983-985, 1983

17. Leung DW, Cachianes G, Kuang WJ, Goeddel DV and Ferrara N: Vascular endothelial growth factor is a secreted angiogenic mitogen. Science 246: 1306-1309, 1989.

18. Xie TX, Wei D, Liu M, Gao AC, Ali-Osman F, Sawaya R and Huang S: Stat3 activation regulates the expression of matrix metalloproteinase-2 and tumor invasion and metastasis. Oncogene 23: 3550-3560, 2004.

19. Xie TX, Huang FJ, Aldape KD, Kang SH, Liu M, Gershenwald JE, Xie K, Sawaya R and Huang S: Activation of stat3 in human melanoma promotes brain metastasis. Cancer Res 66: 3188-3196, 2006.

20. Exadaktylos AK, Buggy DJ, Moriarty DC, Mascha E and Sessler DI: Can anesthetic technique for primary breast cancer surgery affect recurrence or metastasis? Anesthesiology 105: 660-664, 2006

21. Bauer M, Rensing $\mathrm{H}$ and Ziegenfuss $\mathrm{T}$ : Anesthesia and perioperative immune function. Anaesthesist 47: 538-556, 1998 (In German).

22. Borsook D, George E, Kussman B and Becerra L: Anesthesia and perioperative stress: Consequences on neural networks and postoperative behaviors. Prog Neurobiol 92: 601-612, 2010.

23. Marshall L, Khan AH and Buggy DJ: Can anaesthetic and analgesic techniques for cancer surgery affect cancer recurrence and metastasis? Curr Anesthesiology Rep 5: 190-202, 2015.

24. Vahabi S and Eatemadi A: Effects of anesthetic and analgesic techniques on cancer metastasis. Biomed Pharmacother 87: 1-7, 2017.

25. Ogren SO and Holm AC: Test-specific effects of the 5-HT reuptake inhibitors alaproclate and zimelidine on pain sensitivity and morphine analgesia. J Neural Transm 47: 253-271, 1980.

26. Sacerdote P, Bianchi M, Gaspani L, Manfredi B, Maucione A, Terno G, Ammatuna M and Panerai AE: The effects of tramadol and morphine on immune responses and pain after surgery in cancer patients. Anesth Analg 90: 1411-1414, 2000.

27. Yeager MP, Colacchio TA, Yu CT, Hildebrandt L, Howell AL, Weiss J and Guyre PM: Morphine inhibits spontaneous and cytokine-enhanced natural killer cell cytotoxicity in volunteers. Anesthesiology 83: 500-508, 1995.

28. Sasamura T, Nakamura S, Iida Y, Fujii H, Murata J, Saiki I, Nojima $\mathrm{H}$ and Kuraishi Y: Morphine analgesia suppresses tumor growth and metastasis in a mouse model of cancer pain produced by orthotopic tumor inoculation. Eur J Pharmacol 441: 185-191, 2002.

29. Ash SA and Buggy DJ: Does regional anaesthesia and analgesia or opioid analgesia influence recurrence after primary cancer surgery? An update of available evidence. Best Pract Res Clin Anaesthesiol 27: 441-456, 2013.

30. Gupta K, Kshirsagar S, Chang L, Schwartz R, Law PY, Yee D and Hebbel RP: Morphine stimulates angiogenesis by activating proangiogenic and survival-promoting signaling and promotes breast tumor growth. Cancer Res 62: 4491-4498, 2002. 
31. Cao LH, Li HT, Lin WQ, Tan HY, Xie L, Zhong ZJ and Zhou JH: Morphine, a potential antagonist of cisplatin cytotoxicity, inhibits cisplatin-induced apoptosis and suppression of tumor growth in nasopharyngeal carcinoma xenografts. Sci Rep 6: 18706, 2016

32. Rahaman SO, Vogelbaum MA and Haque SJ: Aberrant Stat3 signaling by interleukin-4 in malignant glioma cells: Involvement of IL-13Ralpha2. Cancer Res 65: 2956-2963, 2005.

33. Lamprecht B, Kreher S, Anagnostopoulos I, Jöhrens K, Monteleone G, Jundt F, Stein H, Janz M, Dörken B and Mathas S: Aberrant expression of the Th2 cytokine IL-21 in Hodgkin lymphoma cells regulates STAT3 signaling and attracts Treg cells via regulation of MIP-3alpha. Blood 112: 3339-3347, 2008.

34. Yue P, Zhang X, Paladino D, Sengupta B, Ahmad S, Holloway RW, Ingersoll SB and Turkson J: Hyperactive EGF receptor, Jaks and Stat3 signaling promote enhanced colony-forming ability, motility and migration of cisplatin-resistant ovarian cancer cells. Oncogene 31: 2309-2322, 2012.

35. Sordella R, Bell DW, Haber DA and Settleman J: Gefitinib-sensitizing EGFR mutations in lung cancer activate anti-apoptotic pathways. Science 305: 1163-1167, 2004.

36. Ali SM, Wang K, Johnson A, Rodriguez AA, Elvin JA, Vergilio JA, Suh JH, Chumsri S, Morosini D, Yelensky R, et al: Abstract P6-03-02: EGFR genomic alterations in 5,605 cases of refractory and metastatic breast cancer. Cancer Res 76 (Suppl 4): P6-03-02, 2016.

37. Milagre CS, Gopinathan G, Everitt G, Thompson RG, Kulbe H, Zhong H, Hollingsworth RE, Grose R, Bowtell DD Hochhauser D and Balkwill FR: Adaptive upregulation of EGFR limits attenuation of tumor growth by neutralizing IL6 antibodies, with implications for combined therapy in ovarian cancer. Cancer Res 75: 1255-1264, 2015.

38. Falchook GS, Naing A, Wheler JJ, Tsimberidou AM, Zinner R, Hong DS, Fu S, Piha-Paul SA, Janku F, Hess KR, et al: Dual EGFR inhibition in combination with anti-VEGF treatment in colorectal cancer. Oncoscience 1: 540-549, 2014

39. Engilbertsson H, Aaltonen KE, Björnsson S, Kristmundsson T, Patschan O, Rydén L and Gudjonsson S: Transurethral bladder tumor resection can cause seeding of cancer cells into the bloodstream. J Urol 193: 53-57, 2015.

40. Zhang W, Liu JN and Tan XY: Vaccination with xenogeneic tumor endothelial proteins isolated in situ inhibits tumor angiogenesis and spontaneous metastasis. Int J Cancer 125: 124-132, 2009.

41. Ramírez MF, Huitink JM and Cata JP: Perioperative clinical interventions that modify the immune response in cancer patients. Open J Anesthesiology 3: 133-139, 2013.

42. Wang X, Cao W, Mo M, Wang W, Wu H and Wang J: VEGF and cortactin expression are independent predictors of tumor recurrence following curative resection of gastric cancer. J Surg Oncol 102: 325-330, 2010.

43. Chavira E, Wilson M, Assaf SA, Ingles SA, Llanes A and Chmait R: Anti-angiogenic state in twin-twin transfusion syndrome ameliorated after laser surgery. Ame J Obst Gynecology 206: S52-S52, 2012.

44. Zielinski CE, Mele F, Aschenbrenner D, Jarrossay D, Ronchi F, Gattorno M, Monticelli S, Lanzavecchia A and Sallusto F: Pathogen-induced human TH17 cells produce IFN- $\gamma$ or IL-10 and are regulated by IL-1 $\beta$. Nature 484: 514-518, 2012.

45. O'Connell J, Bennett MW, O'Sullivan GC, Collins JK and Shanahan F: The Fas counterattack: Cancer as a site of immune privilege. Immunol Today 20: 46-52, 1999.

46. Müller CB, De Bastiani MA, Becker M, França FS, Branco MA, Castro MA and Klamt F: Potential crosstalk between cofilin-1 and EGFR pathways in cisplatin resistance of non-small-cell lung cancer. Oncotarget 6: 3531-3539, 2015.
47. Gao SP, Mark KG, Leslie K, Pao W, Motoi N, Gerald WL, Travis WD, Bornmann W, Veach D, Clarkson B and Bromberg JF: Mutations in the EGFR kinase domain mediate STAT3 activation via IL-6 production in human lung adenocarcinomas. J Clin Invest 117: 3846-3856, 2007.

48. Abbott BD, Buckalew AR, DeVito MJ, Ross D, Bryant PL and Schmid JE: EGF and TGF-alpha expression influence the developmental toxicity of TCDD: Dose response and AhR phenotype in EGF, TGF-alpha, and EGF + TGF-alpha knockout mice. Toxicol Sci 71: 84-95, 2003.

49. Weaver CT, Harrington LE, Mangan PR, Gavrieli M and Murphy KM: Th17: An effector CD4 T cell lineage with regulatory T cell ties. Immunity 24: 677-688, 2006.

50. Sen B, Saigal B, Parikh N, Gallick G and Johnson FM: Sustained src inhibition results in signal transducer and activator of transcription 3 (STAT3) activation and cancer cell survival via altered Janus-activated kinase-STAT3 binding. Cancer Res 69: 1958-1965, 2009.

51. Juergens RA and Brahmer JR: Adjuvant treatment in non-small cell lung cancer: Where are we now? J Natl Compr Canc Netw 4: 595-600, 2006.

52. Smith RA and Glynn TJ: Epidemiology of lung cancer. Radiol Clin North Am 38: 453-470, 2000

53. Fossella FV, DeVore R, Kerr RN, Crawford J, Natale RR, Dunphy F, Kalman L, Miller V, Lee JS, Moore M, et al: Randomized phase III trial of docetaxel versus vinorelbine or ifosfamide in patients with advanced non-small-cell lung cancer previously treated with platinum-containing chemotherapy regimens. The TAX 320 non-small cell lung cancer study group. J Clin Oncol 18: 2354-2362, 2000.

54. Herrera B, van Dinther $M$, Ten Dijke $P$ and Inman GJ: Autocrine bone morphogenetic protein-9 signals through activin receptor-like kinase-2/Smad1/Smad4 to promote ovarian cancer cell proliferation. Cancer Res 69: 9254-9262, 2009.

55. Jean GW and Shah SR: Epidermal growth factor receptor monoclonal antibodies for the treatment of metastatic colorectal cancer. Pharmacotherapy 28: 742-754, 2008.

56. Siveen KS, Sikka S, Surana R, Dai X, Zhang J, Kumar AP, Tan BK, Sethi G and Bishayee A: Targeting the STAT3 signaling pathway in cancer: Role of synthetic and natural inhibitors. Biochim Biophys Acta 1845: 136-154, 2014.

57. Song JI and Grandis JR: STAT signaling in head and neck cancer. Oncogene 19: 2489-2495, 2000.

58. Morlacchi P, Robertson FM, Klostergaard J and McMurray JS: Targeting SH2 domains in breast cancer. Future Med Chem 6: 1909-1926, 2014

59. Lapeire L, Hendrix A, Lambein K, Van Bockstal M, Braems G, Van Den Broecke R, Limame R, Mestdagh P, Vandesompele J, Vanhove C, et al: Cancer-associated adipose tissue promotes breast cancer progression by paracrine oncostatin $M$ and Jak/STAT3 signaling. Cancer Res 74: 6806-6819, 2014.

60. Penuel E, Kapp AV, Do A, Tam R, Sumiyoshi T, Marathe C, Sa S, Peale F, Lackner M, Holden S, et al: Biomarker evaluation in a randomized phase 2 study of MEHD7945A (MEHD) versus cetuximab (Cet) in $\geq 2$ line recurrent/metastatic $(\mathrm{R} / \mathrm{M})$ squamous cell carcinomas of the head and neck (SCCHN) [MEHGAN]. Cancer Res 75 (Suppl 15): 1553, 2015.

61. Luwor RB, Baradaran B, Taylor LE, Iaria J, Nheu TV, Amiry N, Hovens CM, Wang B, Kaye AH and Zhu HJ: Targeting Stat3 and Smad7 to restore TGF- $\beta$ cytostatic regulation of tumor cells in vitro and in vivo. Oncogene 32: 2433-2441, 2013. 